\title{
FE COPY
}

\section{U.S. DEPARTMENT OF HEALTH, EDUCATION, AND WELFARE}

CENTER FOR DISEASE CONTROL

NATIONAL INSTITUTE FOR OCCUPATIONAL SAFETY AND HEALTH

CINCINNATI, OHIO 45202

\author{
HEALTH HAZARD EVALUATION DETERMINATION REPORT 73-161-201 \\ SCHULMERICH CARILLONS, INC. \\ SELLERSVILLE, PENNSYLVANIA \\ JUNE 1975
}

\section{TOXICITY DETERMINATION}

Based upon joint environmental and medical evaluations conducted by the National Institute for Occupational Safety and Health (NIOSH) on December 10, 1973, February 20, 1974, and January 29, 1975, it has been determined that exposure to bronze dust within the Hand Bell Tuning Department of Schulmerich Farillons, Inc. is non-toxic. This determination is based upon (1) air measurements for total copper, tin, and lead dusts; (2) medical interviews and cutaneous examinations of exposed employees; (3) biologic sampling of employee's hair, blood and urine, and (4) a review of available literature concerning the toxicity of the substances under consideration.

While the workplace exposure is judged not toxic, an exposure related discoloration of one employee's hair was repeatedly observed. This discoloration is felt by the investigators to represent the formation of a greenish colored reaction product resulting from the interaction of lipid substances normally present on the scalp and hair (probably fatty acids) and finely divided bronze dust. This abnormal coloration was judged to result from direct contact between the substances in question rather than as the result of systemic absorption or toxicity and hence is of only cosmetic significance.

\section{DISTRIBUTION AND AVAILABILITY OF DETERMINATION REPORT}

Copies of this hazard evaluation determination are available upon request from the Hazard Evaluation Services Branch, NIOSH, U.S. Post Office Building, Room 508, 5th and Walnut Streets, Cincinnati, Ohio 45202.

Copies have been sent to:

a. Schulmerich Carillons, Inc.

b. U.S. Department of Labor - Region II

c. NIOSH - Region III 
Page 2 - HHE 73-161

For the purpose of informing "affected employees", the employer shall promptly "post" the Determination Report in a prominent place(s) near where exposed employees work for a period of 30 calendar days.

\section{INTRODUCTION}

Section 20(a)(6) of the Occupational Safety and Health Act of 1970, 29 U.S.C. $669(a)(6)$, authorizes the Secretary of Health, Education, and Welfare, following a written request by any employer or authorized representative of employees, to determine whether any substance normally found in the place of employment has potentially toxic effects in such concentrations as used or found. The National Institute for Occupational Safety and Health received such a request from management at Schulmerich Carillons, Inc. to evaluate exposures to bronze dust in the Hand Bell Tuning Department after noting the occurrence of a greenish hair tinge in an employee of that department.

IV. HEALTH HAZARD EVALUATION

\section{a. Plant process}

Schulmerich Carillons, Inc. is primarily engaged in the manufacture of musical bells, carillons and chimes. Rough cast bronze bells are purchased from an outside source and turned on a lathe to an approximate predetermined pitch. Final tuning and polishing is performed by either of the two employees in the Hand Bell Tuning Department. This is accomplished by repeatedly striking the bell and observing its basic frequency and overtones utilizing an electronic frequency analyzer. Excess metal is systemically ground away from the interior surface of the bell with a hand-held electrically driven drill with a small emory wheel bit as the bel1 is turned by a small lathe. The interior surface is sanded with an emory cloth after the proper pitch has been obtained. After tuning the bell is marked (indexed) with a diamond point stylus at the point where the clapper will produce the optimal note when the bell is struck. Indexed bells are then transferred to an adjacent department (Hand Bell Assembly) where the clapper assembly and handle are affixed to the bell, a final testing performed, and the bells packed for shipment.

\section{b. Evaluation design}

This Department has only two male employees and only one shift is worked. Environmental evaluations were made to assess exposures to airborne bronze dust on December 10, 1973 and February 20, 1974. Both personal and general room respirable and total dust samples were collected. These were analyzed for total dust and copper, tin and lead content. On February 20, 1974, whole blood, urine and hair samples were collected for analys is from both employees. Whole blood samples were analyzed for copper and ceruloplasmin content. 
Page 3 - HHE 73-161

The urine and hair samples were analyzed for copper and the hair was examined by electron microscopy and by microprobe analysis.

For comparative purposes, four NIOSH personnel gave five whole blood samples for copper analysis and ceruloplasmin levels. Five urine samples from four NIOSH volunteers were also analyzed for copper and one NIOSH employee with white hair donated a sample for electron microscopic and microprobe analysis. On January 29, 1975, blood serum samples were obtained from the two employees for copper analysis and four NIOSH employees volunteered serum for the same purpose.

c. Brief discussion of the known pathophysiologic effects of suspected agent

In industry, copper use has been associated with very little morbidity although contact dermatitis and upper respiratory tract irritation have been reported. Copper salts have caused eye irritation and copper fume typical symptoms of metal fume fever. The ingestion of copper sulfate or other copper salts for suicidal purposes has resulted in severe poisoning and even death. In such instances metallic taste, nausea, vomiting and diarrhea are common. More severely affected patients have demonstrated jaundice, renal toxicity and neurologic findings.

Greenish hair and beard discoloration have been known to occur in bronze and copper workers since the time of Bernardio Ramazzini (circa 1700), the father of occupational medicine. It has been reported in coppersmelters, burnishers, and fillers. It has also been reported from brass hair pins. Such sporadic observations have been poorly documented but several reports have described deposits of bluish-green copper "crystals" apparently observed by light microscopy and in only one instance has increased copper content been documented. In all instances the hair involved has either been blond or grey. Water, which has been acidified by fiuoridation processes leeches excessive copper from household water pipes and has been reported to cause green hair when used for bathing.

\section{d. Evaluation methods}

Personal breathing zone total bronze dust samples were collected on cellulose membrane, 0.84 pore size filters using MSA Model G battery powered vacuum pumps at a flow rate of 1.7 1iters per minute. Respirable breathing zone samples were taken using $10 \mathrm{~mm}$ nylon cyclone separators with the same type pumps, flow rate, and filter media used for total bronze dust sampling. In addition a Gast Hi-Vol Pump Model 1531 with a limiting orifice to maintain critical flow of 91 liters/min. was utilized in the general area sampling. Copper, tin, lead and dust analyses were made using atomic absorption and gravimetric methods, respectively. 
Page 4 - HHE 73-161

Blood, urine and hair analyses for copper were made by atomic absorption spectrophotometry methods. The serum ceruloplasmin levels were determined by the immunodiffusion method and expressed in Meloy units. Qualitative copper levels on hair samples and electron microphotographs were made utilizing a JEOL JXA 50A Electron Probe Microanalyzer in an attempt to define and localize the presence of copper in and on the hair. A beam current of $10 \times 10^{-9}$ amperes at $40 \mathrm{KV}$ was used for all microprobe analyses. X-ray maps were taken at a time exposure of 500 seconds.

\section{e. Evaluation criteria}

The occupational health work air standards relevant to the substances of this evaluation as promulgated by the U.S. Department of Labor (Federal Register, Vol. 39, Number 125, June 27, 1974, pp. 23541-43 (Tables 6-1, 2 and 3 ) are as follows:

\begin{tabular}{lc} 
Substance & 8-Hour Time Weighed Average \\
\cline { 2 - 2 } Copper (dust) & $1 \mathrm{mg} / \mathrm{M}^{3 *}$ \\
Tin (inorganic) & $2 " ~$ \\
Lead (inorganic dust) & $0.2^{\prime \prime}$ \\
Total Inert Dust & $15 "$ \\
Respirable Inert Dust & $5 "$
\end{tabular}

${ }^{*} \mathrm{mg} / \mathrm{M}^{3}$ - milligrams of contamination per cubic meter of air.

Threshold limit values (TLV's) for chemical substances and physical agents in work room environment with intended changes for 1974 pub7ished by the American Conference of Governmental Industrial Hygien ists recommends identical values for the above with the excepption of inorganic lead $\left(0.15 \mathrm{mg} / \mathrm{M}^{3}\right)$ and total nuisance dusts $(10 \mathrm{mg} / \mathrm{M} 3)$. This source makes no recommendation concerning respirable nuisance dusts. NIOSH's Criteria Document on inorgannic lead recommends an exposure level not greater than $0.15 \mathrm{mg} . \mathrm{Pb} / \mathrm{M}^{3}$.

Considerable emphasis was placed upon employee interviews and biologic test results because of the unusual nature of the problem which suggested that direct contact between copper-tin alloy (bronze) dust and employee's hair was responsible for the color phenomenon observed. In any event, the above recommended standards do not necessarily represent absolute protection to all individuals since persons may be unusually susceptible or to have pre-existing medical conditions which may be aggravated by nearly any level of exposure. In this situation the available literature 
Page 5 - HHE 73-161

on the subject of hair discoloration from copper dust reveals that only persons with blond or gray hair have been noted to be affected indicating that this is a required pre-existing condition. Thus, suggested air standards can never be the sole basis for work place evaluations. However, it should be pointed out that the Federal Occupational Standard for the above substances does represent the legal minimum level for control. Biologic test results on exposed workers are compared against published values, where they exist, and against a group of NIOSH employees who volunteered specimens. These values are presented in a subsequent section of this report.

\section{f. Evaluation results}

\section{(1) Environmental}

Four total mass personal breathing zone samples rangęd from $1.04-2.53 \mathrm{mg} / \mathrm{M}^{3}$ (average $1.87 \mathrm{mg} / \mathrm{M}^{3}$ ) for dust; $0.01-0.085 \mathrm{mg} / \mathrm{M}^{3}$ (average $.043 \mathrm{mg} / \mathrm{M}^{3}$ ) for copper; and non-detectable to $.001 \mathrm{mg} / \mathrm{M}^{3}$ for tin. These values range from approximately 6 to $15 \%$ of the Federal Standard for total nuisance dust and are less than $10 \%$ and $1 \%$ of the copper and tin standards, respectively.

Two respirable personal breathing zone samples were found to contain the following: dust, 0.58 and $1.50 \mathrm{mg} / \mathrm{M}^{3}$; f̧opper, non-detectable and 0.02 $\mathrm{mg} / \mathrm{M}^{3}$; tin, both less than $0.00025 \mathrm{mg} / \mathrm{M}^{3}$. Thus, for dust the samples averaged about $20 \%$ of the Federal Standard and copper and tin levels were extremely low.

Five general room respirable samples gave the following results upon analvsis: dust, 0.26 to $0.75 \mathrm{mg} / \mathrm{M}^{3}$ (average 0.52 ); copper, 0.01 to $0.05 \mathrm{mg} / \mathrm{M}^{3}$ (average 0.02 ); and tin, 0.001 to $0.00 \mathrm{mg} / \mathrm{M}^{3}$ (average 0.006 ).

Aga in the most significant contaminant, dust, was present in a concentration approximating $10 \%$ of the Federal Standard where on $1 y$ extremely small amounts of copper and tin were present.

Four general room total mass samples were alsp analyzed with the following results: Total dust, 0.36 to $4.86 \mathrm{mg} / \mathrm{M}^{3}$ (average 1.91); Copper, 0.01 to $1.21 \mathrm{mg} / \mathrm{M}^{3}$ (average 0.32 ); Tin, non-detectable to 0.00025 to $0.0003 \mathrm{mg} / \mathrm{M}^{3}$ (average 0.0003 ). Al1 these values are wel1 below Federal standards.

Five samples (two personal total mass, two general room respirable and one general room total mass) were tested for the presence of lead. None was detected in any of the samples. This was not unexpected since bell quality bronze specifications require less than one hundredth percent lead. 
Page 6 - HHE 73-161

From these results it is apparent that only a smal1 percentage ( $5 \%$ or less) of the airborne dust collected represents bronze metal with the remainder representing inert or nuisance dust. Nuisance particulate standards have generally been based primarily on worker comfort rather than on the existence of specific occupational disease associated with excessive exposures. In this study it is presumed that a considerable proportion of the dust generated is from emery paper. In any event all measurements were well below existing or suggested standards.

\section{(2) Medical Results}

Employee Interview and Examination

The affected employee's past medical history is unremarkable except for poliomylitis in 1949. At the time of the investigation he had been employed by Schulmerich Carillons for two years as a hand bell tuner. He began developing gray hair approximately five years ago and was essentially completely gray prior to joining Schulmerich. The greenish coloration was first noted three or four months after bronze dust exposure began. He had noted that the intensity of the greenish color varied directly with his workload. He shampoos regularly with over-the-counter proprietary products and notes no effects upon the greenish color. He uses no other hair preparations of any kind. On examination a distinct greenish-black discoloration of the scalp hair was apparent. This was most prominent on the longer hair combed along the sides of the scalp. Other body hair was unaffected.

A brunet co-worker with even longer service in this Department had noted no discoloration or other hair problems despite virtually identical work practices and exposure. Neither man had any signs or symptoms suggesting copper toxicity.

Whole blood, serum and urine copper levels are presented in Table 1 along with serum cerulopiasmin levels for exposed workers and controls. Despite the extremely small size of the groups, statistically significant increases in serum copper and ceruloplasmin levels were found for the exposed individuals. These differences probably reflect occupational exposure to copper or possibly regional dietary intake variation. Serum ceruloplasmin is a blue protein (alpha 2-glolulin) containing eight atoms of copper per molecule. The function of ceruloplasmin is unknown but it probably functions by binding and releasing copper at various sites in the body thereby regulating copper utilization. It is markedly decreased in a rare inherited neurologic condition--Wilson's disease. Whole blood as well as serum copper levels were obtained since red blood cells are known to contain another copper protein complex of 
Page 7 - HHE 73-161

unknown function, erythrocuprein. In any event while there is a difference between the two groups, all levels reported are well within the range of normal levels reported in the literature. It is also noted that the affected employee had a lower serum copper than his unaffected co-worker.

No differences between the whole blood and urine copper levels for the exposed and unexposed groups was discernible statistically. 
TABLE 1

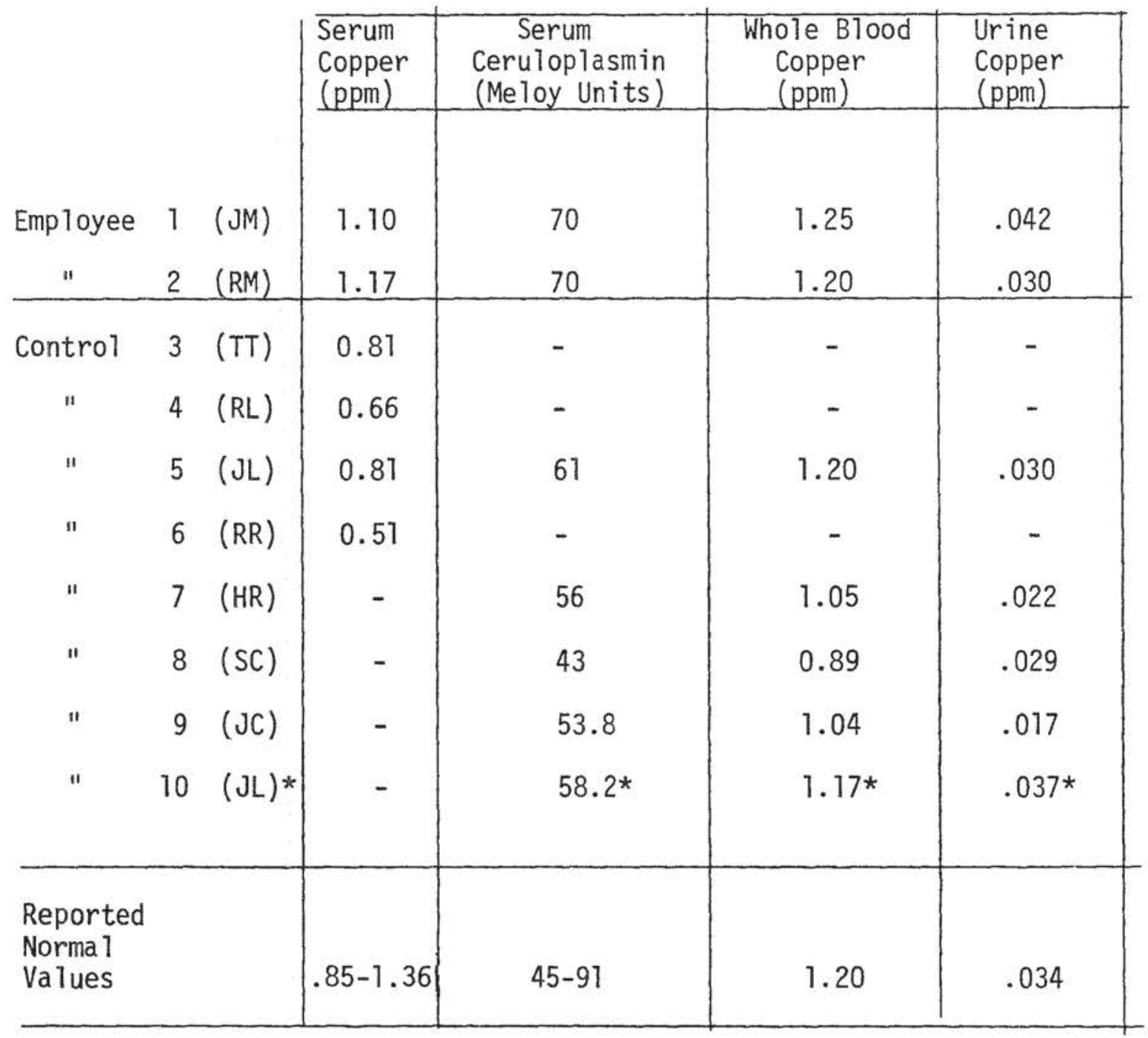

* Split sample - identical with Control \#5

Serum ceruloplasmin was significantly higher for the exposed group compared with the controls $(P=.0293)$ and so were serum copper levels $(P=. .0164)$. Whole blood copper and urine copper levels were not statistically different between the groups-- $P=.1468$ and .2301 , respectively. 
Page 9 - HHE 73-161

Hair copper levels are presented in Table 2. A pre-shampoo sample collected approximately three weeks after the last shampoo from the affected employee showed the presence of large amounts of copper fairly evenly distributed along the hair shaft. These high levels were confirmed by the analysis of a subsequent bulk hair sample obtained at the time of a hair cut and again after abstaining from shampooing. This sample was found to contain $1010 \mu \mathrm{g} / \mathrm{gm}$. of hair.

A post-shampoo hair sample obtained approximately 12 hours after washing demonstrated a marked reduction in copper for all portions of the hair and especially in the copper content of the more distal portions of the hairs which are probably the more thoroughly cleansed in shampooing. The marked reduction in copper following shampooing strongly suggests that this element is present primarily on the surface of the hair and is only loosely bound to the hair.

The unaffected worker's hair was similarly portioned for analysis. He had last shampooed approximately 36 hours previously but had experienced a full work day's exposure to bronze dust prior to the collection of the hair sample. In comparison with a control sample, he also was found to have appreciable amounts of copper present in all hair segments with the greatest concentration noted terminally suggesting that at least some of the copper represents the deposition of airborne bronze dust accumulated during the preceeding shift.

The control's hair samples were found to have low copper levels fairly uniformly distributed along its length. These values are felt to reflect the intrinsic content of copper normally bound to hair protein and are quite consistent with reported hair copper levels for "normal" individuals. 


\section{TABLE 2}

HAIR COPPER LEVELS

(ug/gm)

Portion of Hair Tested

\begin{tabular}{cccc}
\hline Exposed Subjects & $\begin{array}{c}\text { Proximinal } \\
\text { to Scalp }\end{array}$ & Mid-Portion & Terminal End \\
\hline $\begin{array}{c}\text { J.M. } \\
\text { (Pre-shampoo) }\end{array}$ & 683 & 577 & 704 \\
$\begin{array}{c}\text { J.M. } \\
\text { (Post-shampoo) }\end{array}$ & 121 & 70 & 58 \\
\hline $\begin{array}{c}\text { R.M. } \\
\text { (Post-shampoo } \\
\text { 36 hrs.) }\end{array}$ & 155 & 168 & 205 \\
\hline $\begin{array}{c}\text { C.S. } \\
\text { (NIOSH Contro1) }\end{array}$ & 22 & 22 & 16 \\
\hline
\end{tabular}


Page 11 - HHE 73-161

Light microscope, electron microscope and microprobe analysis.

Light microscopy at 100 powers failed to disclose the presence of particulate material on the hair shaft or other abnormalities. Electron miscroscopy also failed to reveal discrete particles and it is concluded that bronze dust per se is not responsible for the discoloration unless the particle size is so small (less than $100 \mathrm{~A}$ ) that it is below the resolution of the instrument. Using electron probe analysis, which is onty roughiy quantitative, copper was identified as present on green hairs and apparently fairly uniformly distributed along the surface of the hair (Figure 1). Copper was not identified in non-greenish or control specimens (Figure 2). Many, but not all greenish hairs, showed some distortion of the normally overlapping scales which constitute the hair cortex (Figure 3). Microprobe analysis did not indicate any association between this loss of normal hair architecture and copper concentration. X-ray mapping for copper demonstrated a very uniform distribution without the presence of "hot spots" which particulate bronze dust might be expected to produce (Figure 4). Unfortunately, attempts at electron probe analysis were technically unsuccessful when applied to cross-sections of the hair and it could not be determined whether the large excess of copper was entirely located on the cortex or evenly distributed between the cortex and medulla. However, from the X-ray maps it would seem unlikely that the copper is centrally located within the hair.

The following points may be summarized from the foregoing environmental and biologic data:

(1) Comparatively little environmental copper is present in the work place air. Most of the airborne bronze particles generated are large in size and rapidly settle out on work and body surfaces with only a small proportion being respirable in size. It is unlikely that the low respirable levels observed could result in a systemic effect.

(2) The amount of copper observed in various body fluids was not greater than previously reported for normal individuals and the differences demonstrated between serum copper and ceruloplasmin levels for the two exposed workmen and controls suggest only slight differences in copper absorption.

(3) Particulate metal dust was not observable upon the hair shafts of affected hairs by the several methods applied.

(4) The copper present on affected hairs is evenly distributed across the hair and is present along its entire length. 
Page 12 - HHE 73-161

(5) Most of the copper present on affected hair was easily removable by washing with commercial shampoo although the greenish discoloration remains discernible.

In conclusion, it is hypothesized that the greenish hair discoloration observed in this instance is due to the formation of greenish copper soaps of fatty acids or other constituents of sebum which normally coat the scalp hair.

Sebum is a complex of lipid substances produced by both sebaceous glands and the cells of the epidermis. These sources produce somewhat different lipids which once mixed cannot be separated. When analyzed two major fractions of sebum are distinguished, i.e., free fatty acids and neutral fats. The latter contains glycerol, combined fatty acids, and a non-saponifiable fraction (paraffins, squalene, waxes, triglycerides, sterols, diglycerides, and phospholipids). The free fatty acids consist almost entirely of saturated and monounsaturated acids of 10 to 18 carbons in length. The major fatty acids are myristic ( $\mathrm{C} 14)$, palmitic (C16), and stearic (C18). These are capable of forming soaps with various metals, including copper. Cupric salts of these fatty acids are greenish-blue in color. It is probable that these soaps can only be visualized when present on white hair being masked by the melanin present in most hair. Such soaps are insoluble in water and are unlikely to be completely removed with various ionic shampoos, but are soluble in many organic solvents.

\section{g. Recommendations}

(1) The affected employee should be provided with close fitting disposable paper caps such as are used by food preparation personnel.

(2) An attempt may be made to remove the offending pigment by rinsing the hair with rubbing alcohol. 


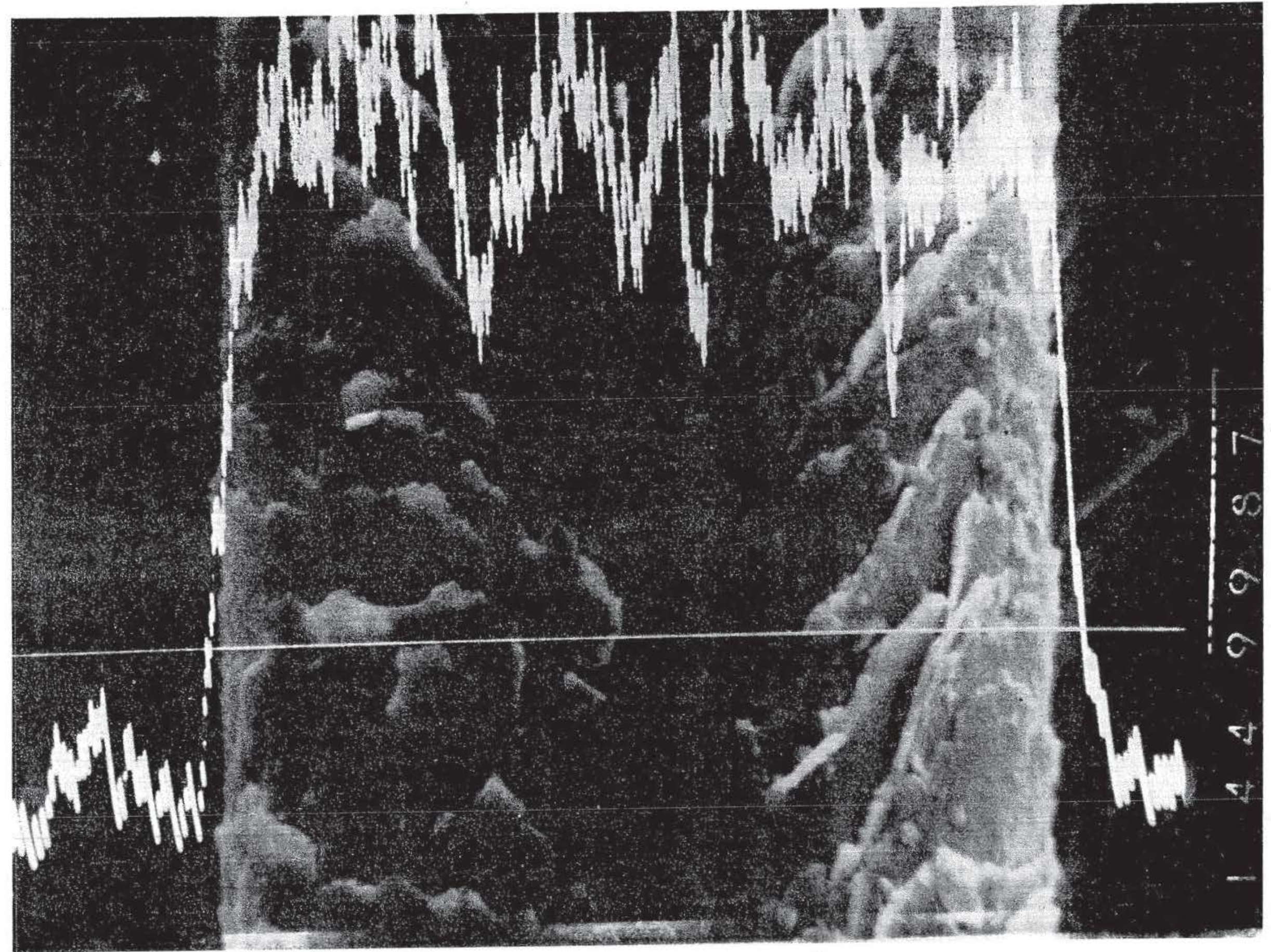

Figure 1. Affected hair showing presence of copper by electron scan 


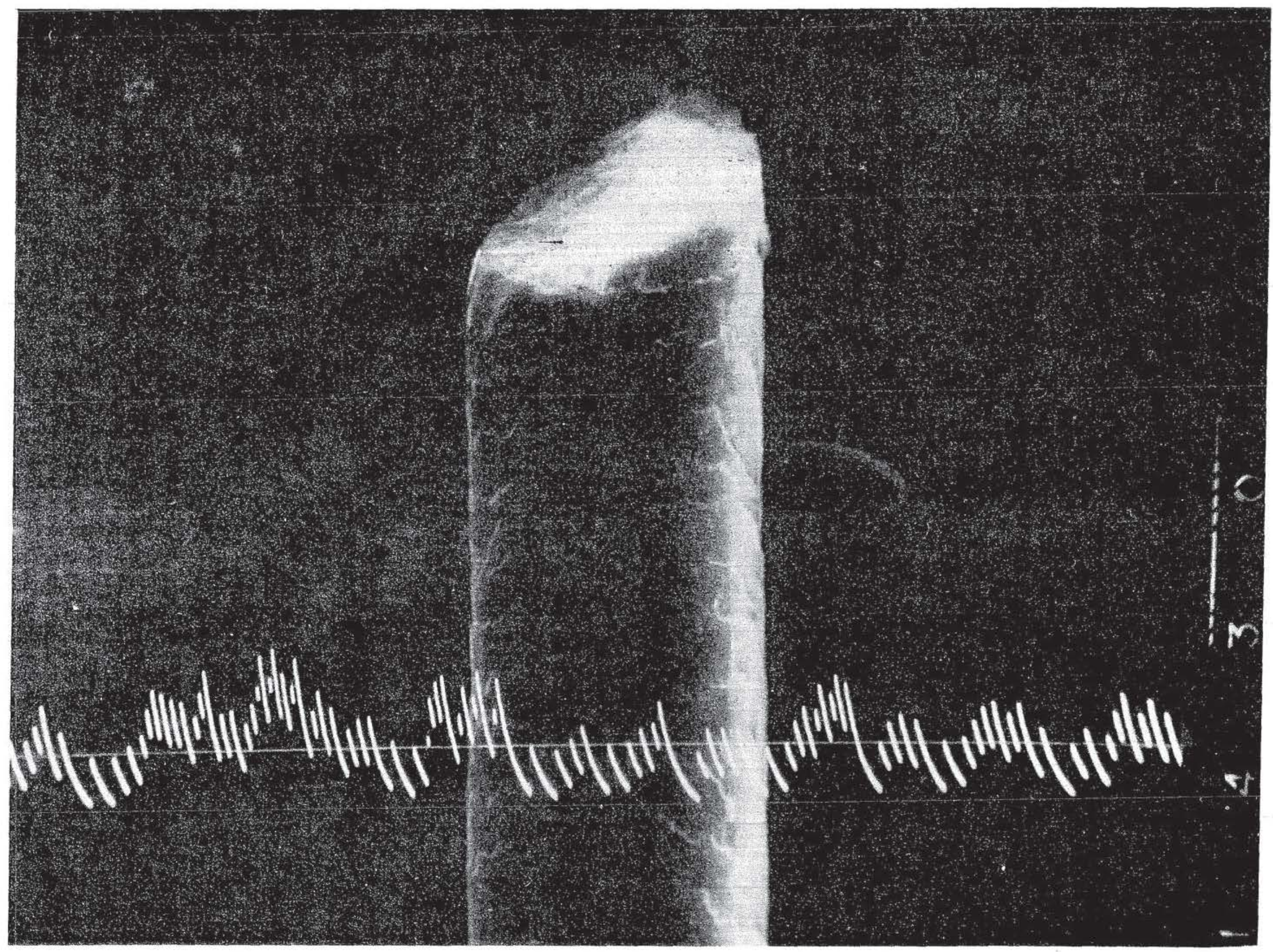

Figure 2. Normal control hair with electron scan showing absence of copper. 


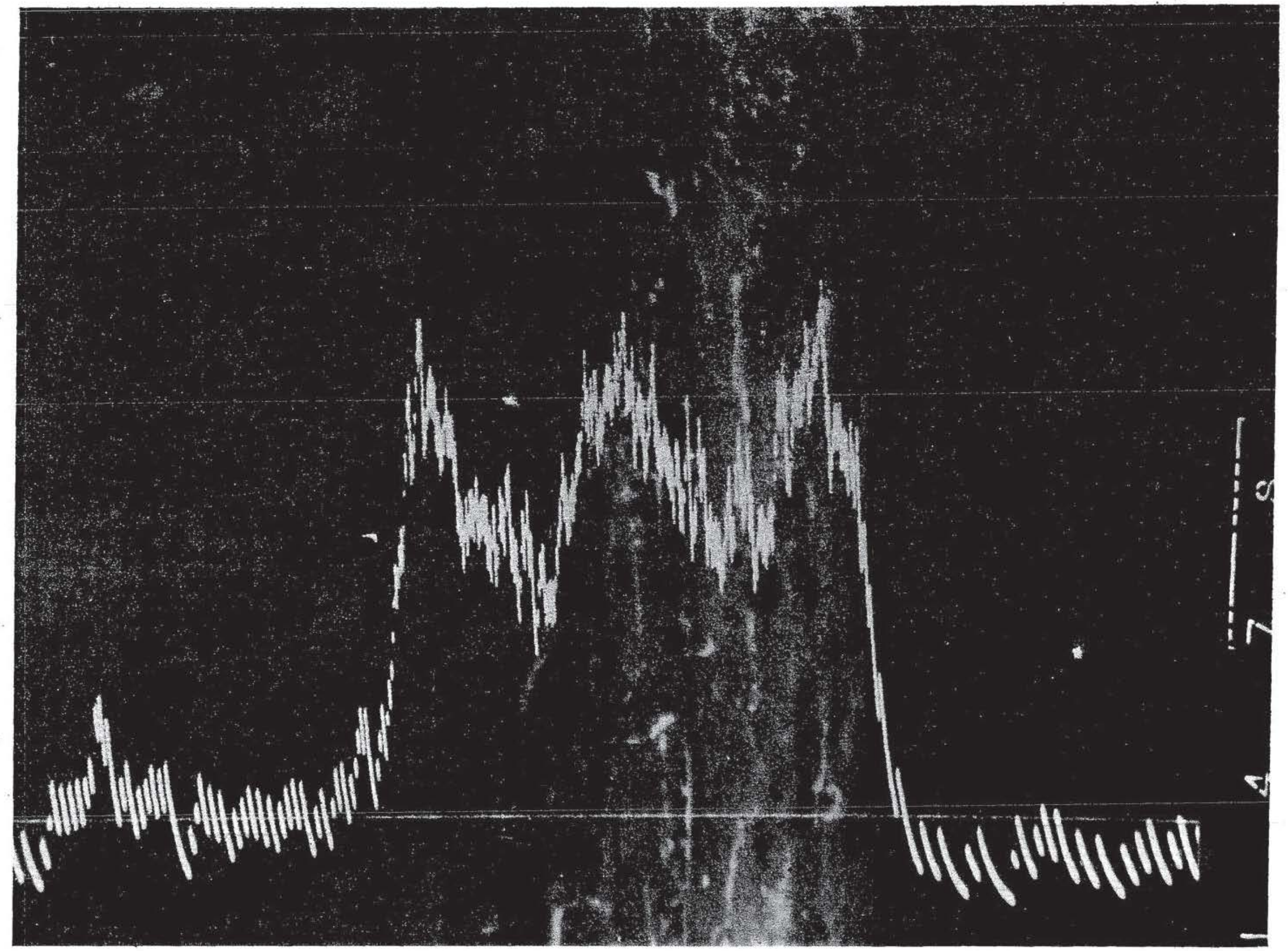

Figure 3. Affected hair demonstrating loss of normal hair morphology 


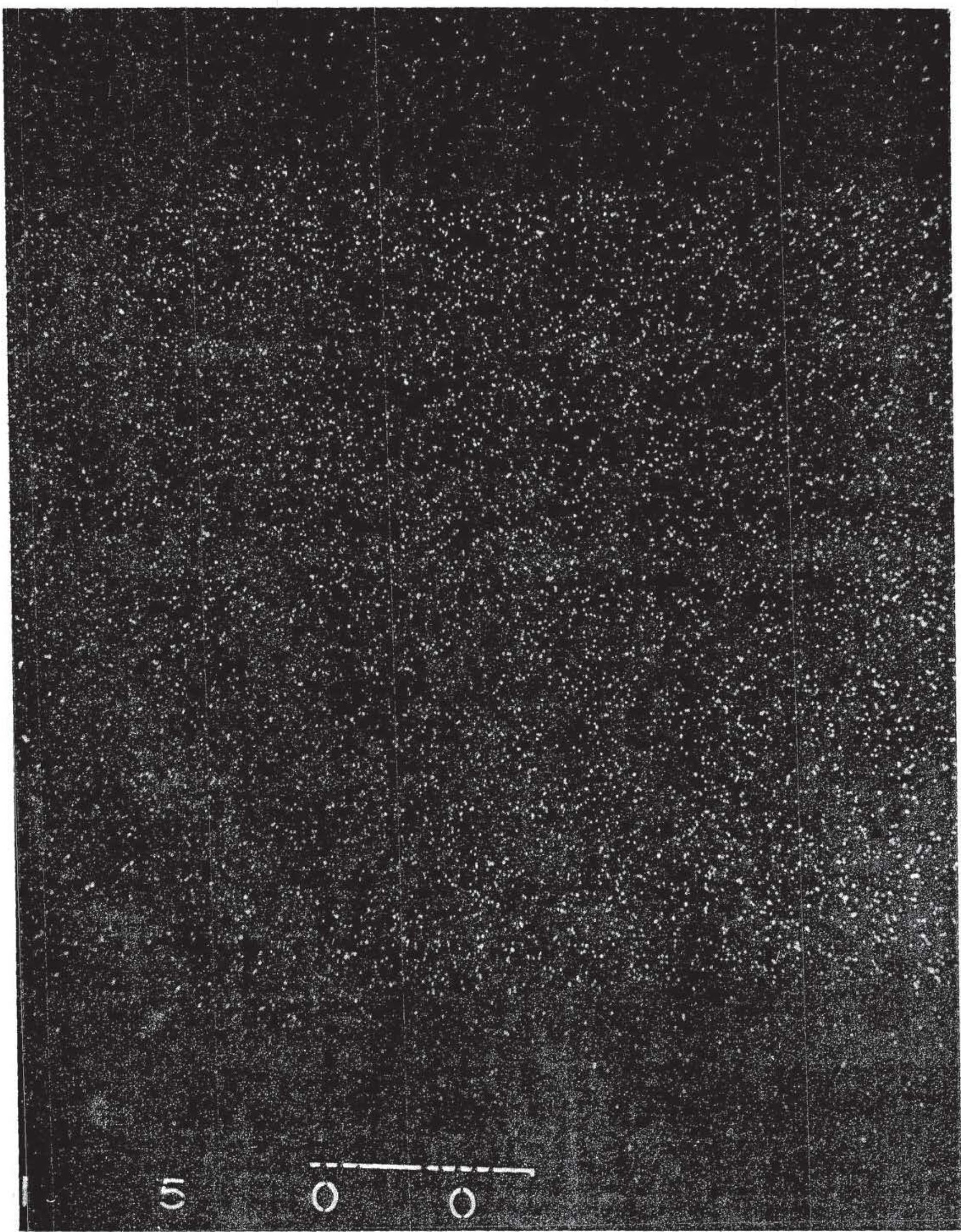

Fiqure 4. X-ray map of affected hair. 